\title{
Antifungal Activity of Microcapsulated Clove (Eugenia caryophyllata) and Mexican Oregano (Lippia berlandieri) Essential Oils against Fusarium
}

\section{oxysporum}

\author{
Carlos Estrada-Cano, María Antonieta Anaya Castro, Layla Muñoz-Castellanos, Nubia Amaya-Olivas Antonio García-Triana* and \\ León Hernández-Ochoa*
}

Universidad Autónoma de Chihuahua, Facultad de Ciencias Químicas. Circuito Universitario, Campus Universitario México

\begin{abstract}
The aim of the present study was to determine the antifungal activity of microcapsules of essential oil of clove (Eugenia caryophyllata) and Mexican oregano (Lippia berlandieri) against Fusarium oxysporum. Different essential oil to $\beta$-cyclodextrin weight ratios were tested, $(4: 96,8: 92,12: 88$ and $16: 84 \mathrm{w} / \mathrm{w})$ and encapsulation efficiency same as rate, were determined. GC-MS and GC-FID analysis were also performed to determine. The main oil constituents, which were eugenol and carvacrol in clove and Mexican oregano essential oils respectively and to quantify their ratio in microcapsules. The oxford cup method was used to determine the antifungal inhibitory activity of essentials oils and microcapsules of essential oils. The results showed that the 4:96 ratio (clove essential oil: $\beta$-cyclodextrin) gave the highest Eugenol content and the greatest microencapsulation efficiency; and the 8:92 and 12:88 ratios (Mexican oregano essential oil: $\beta$-cyclodextrin) gave the highest carvacrol content. The essential oil of cloves and Mexican oregano showed the greatest inhibition values against Fusarium at the beginning of the tests; however, after 8 days of analysis, the microcapsules containing essential oil of clove were the most effective ones. Putting everything together, our findings indicate that the antifungal activity of the $\beta$-cyclodextrin-essential oils capsules, show great promise for the extensive control of Fusarium oxysporum.
\end{abstract}

Keywords: Microcapsules, Clove (Eugenia caryophyllata), Mexican oregano (Lippia berlandieri), Fungicide action, Fusarium oxysporum

\section{Introduction}

Spoilage of foods due to the presence of bacterial and fungal infections has been a major concern for decades and it causes a considerable loss worldwide [1]. One of the strategies for inhibiting undesirable microorganisms is the use of synthetic or natural substances, and the demand for non-toxic, natural preservatives has been rising with an increased awareness, as well as the effects of synthetic chemical oil present in the food [2]. Therefore, alternative sources of safe, effective and acceptable natural preservatives need to be explored, and natural food preservatives flourish due to their strength and nutrient. Fusarium wilt of tomato caused by "Fusarium oxysporum" is one of the most prevalent and damaging diseases that causes considerable losses, especially in susceptible environments and under favorable weather conditions [3]. Although F. oxysporum widely reported as a soil borne pathogen, several studies have indicated that infested seeds may contribute significantly to the dissemination of other Fusarium species that are plant pathogenic fungi [4-6]. Fungicides are used to control this problem. Unfortunately, these chemicals are not readily biodegradable; tend to persist for years in the environment and some fungi have developed resistance to them [7]. The replacement of synthetic products with more natural alternatives is safer when the new product is as effective as the product previously used. The essential oils obtained from spices are among these alternatives, as their active components (including terpenes, aldehydes, acids, alcohols, phenols, esters and ketones) for their antimicrobial activity [8]. Essential oil of Mexican Oregano (Lippia berlandieri) is a mixture of several components, mainly the phenolic monoterpenoids as thymol, carvacrol and their precursor p-cymene [9]. The antimicrobial and antioxidant activities of these compounds are well known and have been reported in many studies [10-14]. Clove bud oil have biological activities, such as antibacterial, antifungal, anticonvulsant, anticarcinogenic, and antimutagenic properties and are used traditionally as flavoring agent and antimicrobial material in food. The high levels of eugenol contained in clove essential oil provide a strong biological activity and antimicrobial activity [15]. Microencapsulation technique has been used for the stabilization of labile compounds, which protects food ingredients against deterioration, volatile losses, or premature interaction with other ingredients [16]. Cyclodextrins represent one of the simplest encapsulate systems. Cyclodextrins are naturally occurring molecules (produced enzymatically from the starch) that take the shape of a truncated cone or torus instead of a perfect cylinder because of the chair conformation of the glucopyranose units. Cyclodextrins have a wide range of practical application in pharmaceutical, cosmetic, food, chemical and several other industries [17-19]. The objective of this work was to evaluate the antifungal activity of microcapsule of essential oil of clove (Eugenia caryophyllata) and Mexican oregano (Lippia berlandieri) against Fusarium oxysporum using oxford cup method.

\section{Materials and Methods}

Fusarium oxysporum used in this study was obtained from the

*Corresponding author: León Hernández-Ochoa: Universidad Autónoma de Chihuahua, Facultad de Ciencias Químicas. Circuito Universitario, Campus Universitario \#2 Chihuahua, México. Tel:+(52)2366000, E-mail: Ihernandez@uach.mx

Antonio García-Triana Universidad Autónoma de Chihuahua, Facultad de Ciencias Químicas. Circuito Universitario, Campus Universitario \#2 Chihuahua México. Tel:+(52)2366000, E-mail: triana.antonio@gmail.com

León Hernández-Ochoa: Universidad Autónoma de Chihuahua, Facultad de Ciencias Químicas. Circuito Universitario, Campus Universitario \#2 Chihuahua, México. Tel:+(52)2366000, E-mail: Ihernandez@uach.mx

Received January 25, 2017; Accepted February 09, 2017; Published February 16,2017

Citation: Estrada-Cano C, Anaya-Castro MA, Muñoz-Castellanos L, AmayaOlivas N, García-Triana A, et al. (2017) Antifungal Activity of Microcapsulated Clove (Eugenia caryophyllata) and Mexican Oregano (Lippia berlandieri) Essential Oils against Fusarium oxysporum. J Microb Biochem Technol 9: 567-571. doi: 10.4172/1948-5948.1000342

Copyright: $\odot 2017$ Cano CE, et al. This is an open-access article distributed under the terms of the Creative Commons Attribution License, which permits unrestricted use, distribution, and reproduction in any medium, provided the original author and source are credited. 
Citation: Estrada-Cano C, Anaya-Castro MA, Muñoz-Castellanos L, Amaya-Olivas N, García-Triana A, et al. (2017) Antifungal Activity of Microcapsulated Clove (Eugenia caryophyllata) and Mexican Oregano (Lippia berlandieri) Essential Oils against Fusarium oxysporum. J Microb Biochem Technol 9: 567-571. doi: 10.4172/1948-5948.1000342

University School of Chemical Science (Universidad Autonoma de Chihuahua) culture collection. Clove (Eugenia caryophyllata) was purchased in Commercial Cardona, Chihuahua, Mexico and clove essential oil was obtained by hydrodistillation process. Essential oil of Mexican oregano (Lippia berlandieri) was acquired in CIRENA (Research Center for Natural Resources, Salaices, Mexico). Eugenol, eugenyl acetate, carvone, carvacrol, thymol, p-cymene and $\beta$-caryophyllene GC standards were purchased from Sigma-Aldrich. $\beta$-cyclodextrin (Cavamax W7 food grade) was kindly supplied by Wacker Biochem, (Mexico). All other reagents used were analytical grade.

\section{Extraction of essential oils}

A modified Schilcher apparatus was utilized in hydrodistillation process. The flow rate was 10 to $15 \mathrm{ml} / \mathrm{min}$. Cooling water was kept at $19^{\circ} \mathrm{C}$ to prevent the higher molecular weight components from being stuck in the cooler. As for clove, $200 \mathrm{~g}$ of the spice was added to $4 \mathrm{~L}$ of water in a boiling flask. The system was heated to $100^{\circ} \mathrm{C}$ during $5 \mathrm{~h}$. The operating conditions depended on the vegetable's material used, according to Hernandez-Ochoa [20].

\section{Microencapsulation process}

Microcapsules of clove essential oil: $\beta$-cyclodextrin and Mexican oregano essential oil: $\beta$-cyclodextrin were prepared separately according to the precipitation method reported by Ayala et al., 2008. A sample of $10 \mathrm{~g}( \pm 0.01)$ of $\beta$-Cyclodextrin was dissolved in $100 \mathrm{~mL}$ of an ethanol-water $(1: 2)$ mixture and maintained at $55^{\circ} \mathrm{C}\left( \pm 2^{\circ} \mathrm{C}\right)$ on a hot stirrer plate. The corresponding amounts of each essential oil ratio $(0$, $0.4168,0.8691,1.3645$ and $1.9049 \mathrm{~g} \pm 0.01 \mathrm{~g}$ ) needed to obtain weight ratios of essential oils to $\beta$-cyclodextrin of $0: 100,4: 96,8: 92,12: 88$ and $16: 84$, respectively, were dissolved in ethanol $(10 \% \mathrm{w} / \mathrm{v})$ and then slowly added to the warm $\beta$-cyclodextrin solution, maintaining agitation and temperature at $55^{\circ} \mathrm{C}\left( \pm 2^{\circ} \mathrm{C}\right)$. Then, the heating was stopped and the final solution was covered and agitated for the next $4 \mathrm{~h}$ and kept overnight to $4^{\circ} \mathrm{C}$. The precipitated oil: $\beta$-cyclodextrin microcapsules were recovered by filtration and then dried in a convection oven at $50^{\circ} \mathrm{C}$ for $24 \mathrm{~h}$, and finally were removed from the oven and allowed to air-dry at $25^{\circ} \mathrm{C}$ in a desiccator for an additional $24 \mathrm{~h}$. The final microcapsules were weighed at equilibrium. The amount of recovered microcapsules (dry basis) was calculated as a percentage by comparing the initial weight of raw materials, to the recovery of microcapsules. Finally, the oil microcapsules were stored at $25^{\circ} \mathrm{C}$. Microencapsulation efficiency and microencapsulation yield was calculated using the following formula:

$$
\begin{aligned}
& \text { microencapsulation effeciency }\left(\frac{w}{w} \%\right)=\frac{\text { Encapsulated essential oil }(\mathrm{mg})}{\text { Initial essential oil }(\mathrm{mg})} * 100 \\
& \text { Microencapsulation yield }\left(\frac{w}{w} \%\right)=\frac{\text { Total mass of microcapsules }}{\beta-\text { cyclodextrin mass }(\mathrm{mg})+\text { essential oil mass }(\mathrm{mg})} * 100
\end{aligned}
$$

Each ratio was analyzed and was prepared in triplicate.

\section{Gas chromatography-mass spectrometry (GC-MS) analysis conditions}

Identification of volatile components of clove and Mexican oregano essential oil before and after the microencapsulation process was carried out by gas chromatography coupled to a mass spectrometer (GC/MS) Perkin-Elmer Auto Systems XL. The capillary column selected was PE-5 (stationary phase methylphenyl silicone 5\%), dimensions of 60 $\mathrm{m}$ in length and $0.25 \mathrm{~m}$ diameter. The operating conditions for each of the two oils were: Column temperature was raised from $55^{\circ} \mathrm{C}$ to $120^{\circ} \mathrm{C}$ at a rate of $8^{\circ} \mathrm{C} / \mathrm{min}$ and held there for $1 \mathrm{~min}$, and then the temperature was raised from 120 to $200^{\circ} \mathrm{C}$ at a rate of $8^{\circ} \mathrm{C} / \mathrm{min}$, and held at this final temperature for $9 \mathrm{~min}$. Carrier gas was helium at a flow rate of $1 \mathrm{~mL} /$ min, and identification of the compounds was based on comparison of their mass spectra with the Saturn library and NIST 98 library data from GC-MS system.

\section{Preparation of microorganism suspensions}

Dextrose agar was used to culture the test fungi. Each strain was transferred from stored slants at $4^{\circ} \mathrm{C}$ to $10 \mathrm{~mL}$ dextrose agar tube and cultivated overnight at $37^{\circ} \mathrm{C}$. A pre-culture was prepared by transferring $1 \mathrm{~mL}$ of this culture to $9 \mathrm{~mL}$ nutrients broth and cultivated for $24 \mathrm{~h}$. The fungi culture was diluted in $10 \mathrm{~mL}$ sterile tween $80 \mathrm{~mL}$ $0,05 \%$ saline solution to obtain and adjusted to a cell suspension of $10^{5}$ $\mathrm{UFC} / \mathrm{mL}$ (colony forming units) using a Neubauer UV spectrometer.

\section{In vitro antifungal activity assay}

Oxford cup method was used to determine the antifungal activity. $0.1 \mathrm{~mL}$ of diluted inoculum $\left(10^{5} \mathrm{UFC} / \mathrm{mL}\right)$ from microorganism suspensions was added to and spread on the surface of warm nutrient agar. Using the methodology described by Wang [2] four treatments was evaluated in the same plates: essential oil of clove, microcapsules of clove, essential oil of Mexican oregano, microcapsules of Mexican oregano (Table 1). The essential oils were used as positive control. Oxford cup $(\phi 7 \mathrm{~mm})$ were then placed on the agar medium and filled with different proportions of microcapsules of essential oils as show in the Table 1 . The plates were incubated for 8 days at $25^{\circ} \mathrm{C}$. The antifungal activity was evaluated by measuring the diameter zone of transparent inhibition versus test microorganism, and the inhibitory effect compared with that of the free microcapsules was calculated according to the following formula:

Inhibition $\%=\left[\left(M_{B}-M_{A}\right) / M_{B}\right] \times 100$

Where $M_{A}$ is the diameter of the growth zone in the experimental disc $(\mathrm{cm})$ and $\mathrm{M}_{\mathrm{B}}$ is the diameter of the growth zone in the control disc $(\mathrm{cm})$.The experiments were repeated three times and data were calculated as means \pm standard deviation.

\section{Statistical Analysis}

Data collected were analyzed by one-way ANOVA with a confidence level of 0.95 and Tukey-Kramer multiple mean comparisons. Data were analyzed using the statistical package MINITAB Release16 (Minitab Inc., USA).

\section{Results and Discussion}

\section{Microencapsulation}

Average microencapsulation yield and microencapsulation efficiency (\%) of essential oils at the equilibrium state are given in Table 2 and show good recoveries obtained for each of the oils during the microencapsulation process. Microencapsulation yield (\%) were a significantly higher $(\mathrm{P}<0.05)$ for the 12:88 and 8:92 ratios compared to the 4:96 and 16:84 for both oil microcapsules. However, it is important to emphasize, that increasing the amount of essential oil, reduces the microencapsulation efficiency because, as has been reported by Ayala

\begin{tabular}{|c|c|}
\hline Essential oils of Mexican oregano & $0.00629 \mathrm{~g}$ \\
\hline Essential oils of clove & $0.00080 \mathrm{~g}$ \\
\hline Microcapsule of Mexican oregano & $0.10066 \mathrm{~g}$ \\
\hline Microcapsule of clove & $0.03303 \mathrm{~g}$ \\
\hline
\end{tabular}

Table 1: Concentration of essentials oils contained in microcapsules and pure essentials oils of clove and Mexican oregano used in oxford cup method. 
Citation: Estrada-Cano C, Anaya-Castro MA, Muñoz-Castellanos L, Amaya-Olivas N, García-Triana A, et al. (2017) Antifungal Activity of Microcapsulated Clove (Eugenia caryophyllata) and Mexican Oregano (Lippia berlandieri) Essential Oils against Fusarium oxysporum. J Microb Biochem Technol 9: 567-571. doi: 10.4172/1948-5948.1000342

[21], saturation of the matrix has been reached, which is confirmed by our values of microencapsulation rates. Indeed, for both essential oils, the maximal encapsulation rate was reached for the 12:88 ratio, as lower values were obtained for the 16:84 ratio suggesting that the maximum essential oil inclusion had been acquired [22]. Microencapsulation efficiency values showed that optimum ratios of essential oil to $\beta$-cyclodextrin during microencapsulation existed at around 8:92 for Mexican oregano essential oil and 4:96 for clove essential oil, where the highest contents of majority molecules present in microcapsules were achieved. Gas chromatography (GC-MS) analysis was used to determine the composition of the essential oils. Eugenol was the major volatile component detected in clove essential oil with eugenyl acetate and $\beta$-caryophyllene in lower amounts. The main molecule detected in Mexican oregano essential oil was carvacrol, in addition to minor constituents such as p-cymene, $\beta$-caryophyllene and thymol. The similarity in composition between the most volatile unencapsulated and encapsulated essential oils is probably due to the small size and polarity characteristics of all the volatile molecules studied, which can easily be included in the $\beta$-cyclodextrin. Overall, the most efficient essential oil microencapsulation ratios (essential oil: $\beta$-cyclodextrin) were: 8:92 in the case of Mexican oregano essential oil, encapsulating $71.22 \%$ carvacrol, and a 4:96 ratio for clove essential oil encapsulating $97.61 \%$ eugenol.

\section{In vitro antifungal activity assay}

(Table 3) To determine the percent inhibition of essential oils and microcapsules obtained versus Fusarium oxysporum was established from the average radial growth until day 8 , the results obtained are shown in Table 3. It is observed that there is a significant difference between diameter values inhibition obtained with essential oils and those obtained with the microcapsules, smaller inhibition values were obtained with the treatment carried out with the essential oil of clove, followed by treatment with essential oil of Mexican oregano and microcapsules Mexican oregano oil, however, the highest values were obtained with the microcapsules containing the essential oil of clove.
This may pose an immediate inhibitory action of essential oil of clove Fusarium oxysporum, and a progressive inhibitory action (controlled release) by the microcapsules containing the essential oil of clove. Antifungal activity of essential oil of clove was previously confirmed by Gupta, they determined the percentage of inhibition clove essential oil at a concentration of $500 \mathrm{ml} / \mathrm{L}$ of solution, and these values are similar to those obtained in the present study. This effect can be attributed to its volatile constituents, i.e., eugenol and cinnamaldehyde [21,23]. The antifungal mechanisms of these compounds can be explained by their inhibition of the fungal cell wall synthesizing enzymes $(\beta-(1,3)$-glucan and chitin synthases) by cinnamaldehyde [24]. Carrasco et al. reported almost the antifungal mechanism of eugenol as a disruption of both the membranes and the cell walls of yeast [25]. Cueto-Wong determined minimum inhibitory concentrations of essential oil Mexican oregano (Lippia berlandieri) against Fusarium oxysporum at a concentration of $0.2 \mathrm{~mL} / \mathrm{L}$, considering that the density of the oil $(0.919441 \mathrm{~g} / \mathrm{ml})$, equivalent to $183.88 \mathrm{mg} / \mathrm{L}$ [4]. These results agree with those obtained in this study and demonstrate that the essential oil of cloves is much more effective against Fusarium oxysporum fungus that the essential oil of oregano. In the case of microencapsulated essential oils, you can see that the microcapsules containing Mexican oregano were the most effective, however, according to the statistical analysis of the mean radial growth of Fusarium oxysporum to treatment with pure essential oils and microencapsulated showed no significant difference $\mathrm{P}>0.05$ (Tukey-analysis stockings Kramer), i.e., the same trend of inhibition in all four treatments tested with respect to control was observed (Figure 1). In Figure 1 the kinetics of growth of Fusarium oxysporum shown up to 8 days of growth, be observed until day 3 fungal growth was the same in all treatments performed, however, on that day, the essential oil clove and Mexican oregano essential oil began to show an inhibitory effect on the development of the fungus, as a clear decrease in growth compared to the control was observed. At the end of the study (day 8) the values obtained for treatments with essential oils were the lowest values, indicating an immediate inhibitory effect, however, the values obtained by the microencapsulated have an inhibitory effect but a timespan higher. This effect can be attributed to a more

\begin{tabular}{|c|c|c|c|c|}
\hline $\begin{array}{c}\text { Proportion } \\
\text { Essential oil: } \beta \text {-cyclodextrin }\end{array}$ & Total volatiles (mg/L) & Microencapsulation yield (\%)* & Microencapsulation efficiency (\%) & Microencapsulation rate \\
\hline \multicolumn{5}{|l|}{ Mexican oregano: $\beta$-cyclodextrin } \\
\hline $4: 96$ & $18.58^{d}$ & $89.22^{\mathrm{b}}$ & $54.95^{\mathrm{b}}$ & $2.20^{\mathrm{d}}$ \\
\hline $8: 92$ & $50.13^{c}$ & $93.69^{a}$ & $71.40^{\mathrm{a}}$ & $5.71^{\mathrm{c}}$ \\
\hline $12: 88$ & $63.99^{a}$ & $93.10^{\mathrm{a}}$ & $57.65^{b}$ & $6.92^{\mathrm{a}}$ \\
\hline $16: 84$ & $61.43^{b}$ & $88.71^{\mathrm{b}}$ & $39.46^{c}$ & $6.32^{\mathrm{b}}$ \\
\hline \multicolumn{5}{|l|}{ clove: $\beta$-cyclodextrin } \\
\hline $4: 96$ & $20.55^{c}$ & $88.10^{c}$ & $61.11^{\mathrm{a}}$ & $2.44^{\mathrm{b}}$ \\
\hline $8: 92$ & $32.60^{\mathrm{b}}$ & $94.98^{\mathrm{a}}$ & $46.52^{\mathrm{b}}$ & $3.72^{\mathrm{a}}$ \\
\hline $12: 88$ & $36.98^{\mathrm{a}}$ & $92.17^{\mathrm{b}}$ & $33.46^{c}$ & $4.44^{\mathrm{a}}$ \\
\hline $16: 84$ & $38.90^{\mathrm{a}}$ & $88.67^{c}$ & $25.32^{\mathrm{d}}$ & $4.05^{\mathrm{a}}$ \\
\hline
\end{tabular}

* (Final oil: $\beta$-cyclodextrin ratio weight/Initial oil: $\beta$-cyclodextrin ratio weight) ${ }^{*} 100$ ( $\mathrm{g}$, dry weight)

a,b,c Superscripts with the same letters in the same column didn't present significant difference $\mathrm{P}>0.5$ (Tukey-Kramer multiple mean comparisons)

Table 2: Recoveries of clove and Mexican oregano essential oils microcapsules at various ratios of essential oil versus $\beta$-cyclodextrin.

\begin{tabular}{|c|c|}
\hline Treatment & Diameter of inhibition zone (cm) \\
\hline Control & $1.96 \pm 0.36$ \\
\hline Essential oils of Mexican oregano & $0.51 \pm 0.25$ \\
\hline Essential oils of clove & $0.46 \pm 0.10$ \\
\hline Microcapsule of Mexican oregano & $0.85 \pm 0.26$ \\
\hline
\end{tabular}

Table 3: Antifungal activity of essential oils and microcapsules against Fusarium oxysporum after 8 days of analysis. 
Citation: Estrada-Cano C, Anaya-Castro MA, Muñoz-Castellanos L, Amaya-Olivas N, García-Triana A, et al. (2017) Antifungal Activity of Microcapsulated Clove (Eugenia caryophyllata) and Mexican Oregano (Lippia berlandieri) Essential Oils against Fusarium oxysporum. J Microb Biochem Technol 9: 567-571. doi: 10.4172/1948-5948.1000342

rapid diffusion of essential oils with respect to microencapsulated essential oils. Authors like Del Toro-Sánchez et al., they assessed the controlled release of volatile compounds antifungals thyme essential oil contained in capsules $\beta$-cyclodextrins observed that encapsulation allows controlled and passive release of the antimicrobial agent, compared to the pure essential oils [22] (Figure 2). These results shown in Figure 1 can be confirmed by images obtained and shown in Figure 2, in which the mycelial growth of Fusarium oxysporum was observed at 3, 5 and 8 days of exposure to the pure essential oils and oils encapsulated essential and compared to the control. We can see that there is decrease in fungal growth in all treatments except control. Also, the treatments adversely affected the pigmentation of the fungus that is not the characteristic pigmentation of the fungus, ranging from white to peach before reaching a purple color, watching this change from day 3 over the control was observed. It is noteworthy that no change was observed microscopically in the morphology of hyphae or conidia production in fungus. These results can be explained, considering the time it takes the microencapsulated to release a concentration capable of inhibiting fungal growth, this concentration allows the fungus to grow until the released molecule microencapsulated begins to exert an inhibitory effect, so is not able to match the inhibitory effect of pure essential oil, however, despite the fungus fails to develop a little, the microencapsulated not give you enough to produce structures of resistance as chlamydospores time. Some authors like Hamini-Kadar et al. observed a complete inhibition of Fusarium oxysporum using clove essential oil (Eugenia caryophyllata) at a concentration of $500 \mathrm{ppm}$ [26]. The similar results were observed by Boulenouar et al. when they tested seven essential oils studied, two (anise and clove) were highly effective against fungi tested Aspergillus niger, Aspergillus clavatus, Penicillium sp. and Fusarium sp. [27].

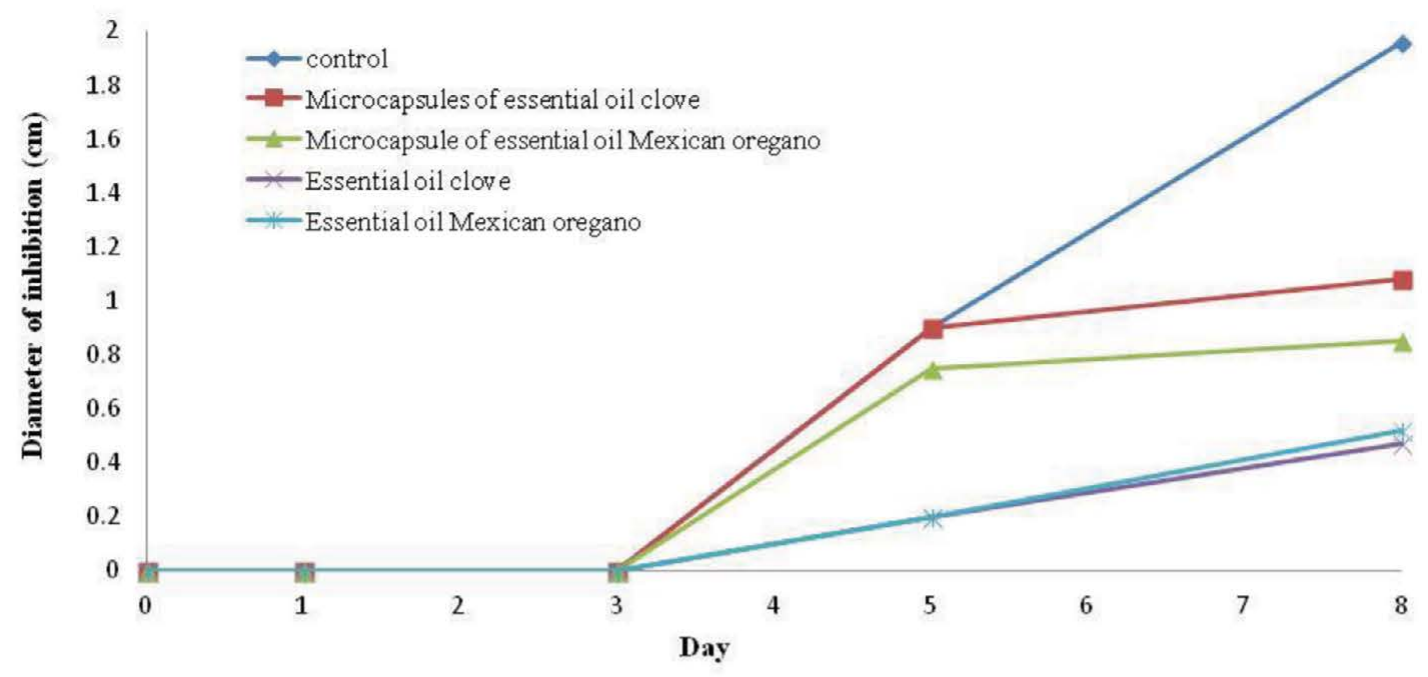

Figure 1: Growth inhibition of Fusarium oxysporum by different treatments.

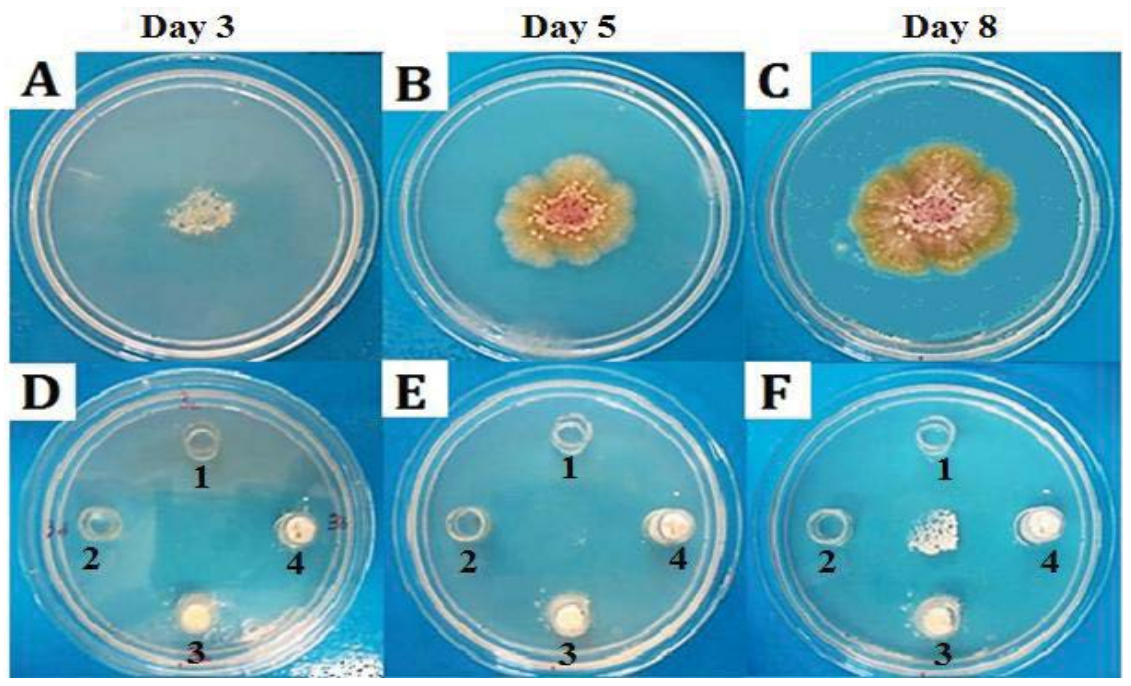

A: control, B: control Fusarium oxysporum day 3, C: control Fusarium oxysporum day 8, D: Treatments 1) Essential oils of clove, 2) Essential oil of oregano, 3) Microcapsules of clove 4) Microcapsules of Mexican oregano day 3, E: Treatments day 5, F: Treatments day 8

Figure 2: Mycelial growth and sporulation of Fusarium oxysporum at 3, 5 and 8 days of analysis. 
Citation: Estrada-Cano C, Anaya-Castro MA, Muñoz-Castellanos L, Amaya-Olivas N, García-Triana A, et al. (2017) Antifungal Activity of Microcapsulated Clove (Eugenia caryophyllata) and Mexican Oregano (Lippia berlandieri) Essential Oils against Fusarium oxysporum. J Microb Biochem Technol 9: 567-571. doi: 10.4172/1948-5948.1000342

Similar type of study was conducted by Deng et al and reported the sensitivity of Fusarium spp. against all the tested essential oils, but cloves oil was found most effective among the tested one [28]. The main chemical components of clove oils are eugenol, acetyl eugenol, iso-eugenol and $\beta$-caryophyllene $[29,30]$. These phenolic compounds are responsible for the antibacterial and antifungal properties of essential oil [31,32].

\section{Conclusion}

In this study, we produced microcapsules using $\beta$-ciclodextrin and essential oils of clove and Mexican oregano by oxford cup method, analyzed its chemical composition of the microcapsules and antifungal activity in vitro of essential oils and essential oils microencapsulates against Fusarium oxysporum, Taken together, our findings indicate that the antifungal activity of the $\beta$-ciclodextrin-essential oils capsules show great promise for the control of Fusarium oxysporum. Therefore, we believe that the $\beta$-ciclodextrin-essential oil clove capsules could be a strong candidate as a safe and highly effective fungicidal microcapsule. However, further studies of its applications on an in vivo scale are required.

\section{References}

1. Chen Z, Zhu C (2011) Modelling inactivation by aqueous chlorine dioxide of Dothiorella gregaria Sacc. and Fusarium tricinctum (Corda) Sacc. spores inoculated on fresh chestnut kernel. Lett Appl Microbiol 52: 676-684.

2. Wang Y, Shao J, Zhou Ch, Zhang D, Bie X, et al. (2009) Food preservation effects of curcumin microcapsules. Food control 27: 113-117.

3. La Torre A, Caradonia F, Matere A, Battaglia V (2016) Using plant essential oils to control Fusarium wilt in tomato plants. Eur J Plant Pathol 144: 478-496.

4. Cueto-Wong $M$, Rivas-Morales $C$, Alanís-Guzmán $M$, Oranday-Cárdenas $A$, Amaya-Guerra C, et al. (2010) Antifungal properties of essential oil of Mexican oregano (Lippia berlandieri) against Fusarium oxysporum f. sp. lycopersici. Revista. Mexicana de Micologia 31: 29-35.

5. Bennett RS, Hutmacher RB, Davis RM (2008) Seed transmission of Fusarium oxysporum f. sp. vasinfectum race 4 in California. The Journal of Cotton Science 12: 160-164

6. Ochoa JB, Ellis MA (2002) Seed transmission of Fusarium oxysporum in common Naranjilla (Solanum quitoense) in Ecuador. Plant Health Progress.

7. Komárek M, Cadková E, Chrastný V, Bordas F, Bollinger JC (2010) Contamination of vineyard soils with fungicides: A review of environmental and toxicological aspects. Environ Int 36: 138-151.

8. Ortuño MF (2006) Practical handbook of essential oils and perfumes (5th ed) España: Ed: Aiyana.

9. Arana-Sánchez A, Estarrón-Espinosa M, Obledo-Vázquez EN, PadillaCamberos E, Silva-Vázquez R, et al. (2010) Antimicrobial and antioxidant activities of Mexican oregano essential oils (Lippia graveolens H. B. K.) with different composition when microencapsulated in ß-cyclodextrin. Lett Applied Microb 50: 585-590.

10. Baranauskiené R, Petras R, Koen D, Roland V (2006) Properties of oregano (Origanum vulgare L.) citronella (Cymbopogon nardos G.) and marjoram (Majorana hortensis L.) flavors encapsulated into milk protein-based matrices. Food Res Int 39: 413-425.

11. Castillo-Herrera G, García-Fajardo J, Estarrón-Espinosa M (2007) Extraction method that enriches phenolic content in oregano (Lippia graveolens H.B.K) essential oil. Journal of Food Processing Engineering 30: 664-673.

12. Liolios C, Gortzi O, Lalas S, Tsaknis J, Chinou I (2009) Liposomal incorporation of carvacrol and thymol isolated from the essential oil Origanum dictamnus $\mathrm{L}$ and in vitro antimicrobial activity. Food Chem 112: 77-83

13. Hammer KA, Carson CF, Riley TV (1999) Antimicrobial activity of essential oils and other plant extracts. J Appl Microbiol 86: 985-990.

14. Rivero-Cruz I, Duarte G, Navarrete A, Bye R, Linares E, et al. (2011) Chemical composition and antimicrobial and spasmolytic properties of Poliomintha longiflora and Lippia graveolens essential oils. J Food Sci 76: 309-317.
15. Wenqiang G, Shufen L, Ruixiang Y, Shaokun T, Can Q (2007) Comparison of essential oils of clove buds extracted with supercritical carbon dioxide and other three traditional extraction methods. Food Control 101: 1558-1564.

16. Dursch S, Schwars K (2006) Microencapsulation properties of two different types of octenylsuccinate derivatised starch. Eur Food Res Technol 222: 155-164.

17. Buvári-Barcza A, Barcza $L$ (1999) Influence of the guests, the type and degree of substitution on inclusion complex formation of substituted beta-cyclodextrins. Talanta 49: 577-585

18. Vyas A, Saraf S, Saraf S (2008) Cyclodextrin based novel drug delivery systems. J Incl Phenom Macrocycl Chem 62: 23-42.

19. Carvalho LB, Pinto LM (2012) Formation of inclusion complexes and controlled release of atrazine using free or silica-anchored ß-cyclodextrin. J Incl Phenom Macrocycl Chem 74: 375-381.

20. Hernández-Ochoa L, Aguirre-Prieto YB, Nevárez-Moorillón GV, GutierrezMendez N, Salas-Muñoz E (2014) Use of essential oils and extracts from spices in meat protection. J Food Sci Technol 51: 957-963.

21. Ayala-Zavala J, Soto-Valdez H, González-León A, Álvarez-Parrilla E, MartinBelloso O, et al. (2008) A Microencapsulation of cinnamon leaf (Cinnamomum zeylanicum) and garlic (Allium sativum) oils in ß-cyclodextrin. J Incl Phenom Macrocycl Chem 60: 359-368.

22. Del Toro C, Ayala J, Machi L, Santacruz H, Villegas M, et al. (2010) Controlled release of antifungal volatiles of thyme essential oil from ß-cyclodextrin capsules. J Incl Phenom Macrocycl Chem 67: 431-441.

23. Singh S, Maurya MP, Lampasona ANC (2006) Chemical composition, antifungal, antioxidant and sprout suppressant activities of coriander (Coriandrum sativum) essential oil and its oleoresin. Journal of Flavor and Fragrance 21: 472-479.

24. Bang KH, Lee DW, Park HM, Rhee YH (2000) Inhibition of fungal cell wall synthesizing enzymes by trans cinnamaldehyde. Biosci Biotechnol Biochem 64: 1061-1063.

25. Carrasco H, Raimondi M, Svetaz L, Di Liberto M, Rodriguez M, et al. (2012) Antifungal activity of eugenol analogues influence of different substituents and studies on mechanism of action. Molecules 17: 1002-1024.

26. Hamini-Kadar N, Hamdane F, Boutoutaou R, Kihal M, Henni JE (2014) Antifungal activity of clove (Syzygium aromaticum L.) essential oil against phytopathogenic fungi of tomato (Solanum lycopersicum L.) in Algeria. J Exp Biol 2: 447-454.

27. Boulenouar N, Marouf A, Cheriti A, Belboukhari N (2012) Medicinal plants extracts as source of antifungal agents against Fusarium oxysporum f. $\mathrm{sp}$. albedinis. J Agric Sci 14: 659-669.

28. Deng J, Li W, Peng XL, Hao XH (2013) Study on the potential of antifungal activity of essential oils against fungal pathogens of fruits and vegetables. $J$ Chem Pharm Res 5: 443-446.

29. Fichi G, Flamini G, Giovanelli F, Otranto D, Perrucci S (2007) Efficacy of an essential oil of Eugenia caryophyllata against Psoroptes cuniculi. Exp Parasitol 115: $168-172$

30. Rahimi AA, Ashnagar A, Nikoei H (2012) Isolation and characterization of 4-allyl-2-methoxyphenol (eugenol) from clove buds marketed in Tehran city of Iran. Int J Chem Tech Res 4: 105-108.

31. Ayoola GA, Lawore FM, Adelowotan T, Aibinu IE, Adenipekun E, et al. (2008) Chemical analysis and antimicrobial activity of the essential oil of Syzigium aromaticum (clove). African Journal of Microbiology Research 2: 162-166.

32. Agrios G (2007) Fitopatologia (2th ed). México: Ed. Limusa (Chapter 11). 